\title{
HIGHLY SELECTIVE AND SENSITIVE ELECTROCHEMICAL BIOSENSOR BASED ON ELECTROCHEMICALLY REDUCED GRAPHENE OXIDE FOR DETECTION OF MIRNA AS A CANCER BIOMARKER
}

\author{
${ }^{1}$ Veronika VANOVA, ${ }^{1,2}$ Eliska SEDLACKOVA, ${ }^{1,2}$ David HYNEK, ${ }^{1,2}$ Lukas RICHTERA, \\ 1,2Zuzana BYTESNIKOVA, ${ }^{1,2}$ Vojtech ADAM \\ ${ }^{1}$ Department of Chemistry and Biochemistry, Mendel University in Brno, Czech Republic, EU, \\ veronikavanova15@gmail.com
}

${ }^{2}$ Central European Institute of Technology, Brno, University of Technology, Brno, Czech Republic, EU

https://doi.org/10.37904/nanocon.2019.8615

\begin{abstract}
Nowadays, cancer is one of the most outrageous diseases affecting millions of people throughout the world. In this study, the sensitive biosensor for miRNA-21 detection was developed. Through a facile sulfonamide coupling reaction a miRNA-21 specific DNA hybridization probe was immobilized onto a glassy carbon electrode (GCE) modified with electrochemical reduced graphene oxide (erGO). miRNA is a small non-coding RNA molecule which plays an important role in gene expression. The level of miRNA in extracellular fluids varying in the presence of cancer and it can serve as potential biomarker for early detection of cancer. An elevated level of miRNA-21 represents a common feature of pathological cell growth or cell stress and is connected with almost all types of cancer and with cardiovascular diseases, as well.

The aim of this study was improve the electrochemical properties by using erGO as a modification for better sensitivity of the developed biosensor. After the modification with erGO, 1-amino-2-naphthol-4-sulfonic acid (AN-SO $3_{3}$ ) was electrodeposited on the GCE surface. --Finally, the amino terminated capture probe was immobilized on the GCE via the sulfonamide coupling reaction. The developed biosensor for the detection of specific miRNA sequence was optimized and modified for using in further experiments.
\end{abstract}

Keywords: Reduced graphene oxide, miRNA, biosensor, electrochemical detection

\section{INTRODUCTION}

Nowadays, one of the most studied potential biomarker for early-phase cancer detection is a microRNA (miRNA) molecule. miRNAs are small non-protein coding sequences, long approximately around 19-25 nucleotides. Cancer is most studied disease, because of its broad widespread occurrence. An early-stage detection of this disease could be a key for saving millions of lives. miRNA plays an important role in the various physiological processes such as cell development, differentiation, immune system and expression of large number of genes [1,2]. The expression of miRNAs is specific in tissues and tumours. Abnormal levels in tumours have a profound role in disease development. In general, miRNA is divided into two groups, tumour suppressor and oncogenic miRNA. In the presence of cancer, the level of tumour suppressor miRNA is lower in body fluids. On the other hand, the level of oncogenic miRNA in the presence of cancer is higher incomparison with the non-cancerous state. One of the most studied oncogenic miRNAs is miRNA-21, which is associated with prostate, ovarian, breast, and lung cancer. The role of miRNA as a biomarker lies in tracing the level of miRNA in the body fluids such as urine, blood serum, saliva, etc. [2]. The level of miRNA in afore mentioned fluids is very low (nano, femtomolar), that is why selective and sensitive detection of miRNA is more than necessary. One of the most promising approaches for the detection of miRNA is using electrochemical biosensor. This method is known for its capability to measure very low concentrations, in short analysis time with cheaper instrumentation, the possibility of miniaturization and possibility of parallel detection of large number of samples. Compared to the most commonly used conventional methods such as Northern blotting 
or RT-PCR, which are often time-consuming, laboriousness and expensive, biosensors have real potential in the future.

In this work, we prepared a sensitive, label-free biosensor, based on GCE modified with erGO and $\mathrm{AN}_{-} \mathrm{SO}_{3}-$ electrodeposition with sulfonamide coupling reaction for immobilization of oligonucleotide's probe selective for oncogenic miRNA-21. Graphene-family nanomaterials have various essential features and are used in diverse areas, especially for anti-microbial action, cancer therapy, pathogen bio-detection, etc. The ability of erGO to enhance the sensitivity of the biosensor was utilised in this experiment. In the terms of electrical conductivity, graphene oxide (GO) is reported as an insulator. On the other hand, the reduction of $G O$ is increasing the electrical conductivity [3].

\section{MATERIALS AND METHODS}

\subsection{Chemicals}

Chemicals used in this study were purchased from Sigma-Aldrich (St. Louis, MO, USA). The deionized water was prepared using reverse osmosis equipment Aqual 25 (Aqua Osmotic, Tisnov, Czech Republic). The resistance was $18.2 \mathrm{M} \Omega \cdot \mathrm{cm}$. The $\mathrm{pH}$ was measured using $\mathrm{pH}$ meter WTW inoLab (Weilheim, Germany).

Phosphate buffered saline (PBS) $25 \mathrm{mM} \mathrm{pH}$ 7, was prepared by mixing $20.0 \mathrm{~g} \mathrm{NaCl}, 0.5 \mathrm{~g} \mathrm{KCl}, 3.6 \mathrm{~g} \mathrm{Na}_{2} \mathrm{HPO}_{4}$ and $0.6 \mathrm{~g} \mathrm{KH}_{2} \mathrm{PO}_{4}$ into $1000 \mathrm{ml}$ of MilliQ water. $10 \mathrm{mM}$ 1-amino-2-naftol-4-sulfonic acid ( $\left.\mathrm{AN}^{-\mathrm{SO}_{3}-}\right)$ was diluted in PBS. Other used chemicals: $40 \mathrm{mM} \mathrm{PCl}_{5}$ in acetone, Tris-EDTA (TE buffer) $\mathrm{pH}$ 8. All measurements were taken in $5 \mathrm{mM}$ potassium ferro/ferri cyanide and $0.1 \mathrm{M} \mathrm{KCl}$. GO was prepared according to the procedure previously described [5]. The sequences of the oligonucleotides used:

DNA probe (anti-miRNA-21): 5'-NH2-C6-TCAACATCAGTCTGATAAGCTA-3'

miRNA-21: 5'-UAGCUUAUCAGACUGAUGUUGA-3'.

\subsection{Electrode cleaning}

The glassy carbon electrode (GCE) was polished by using $1.0 ; 0.3 ; 0.05 \mu \mathrm{m}$ Alumina slurry and $0.5 \mu \mathrm{m}$ diamond suspension each for $90 \mathrm{~s}$. Between each step, electrodes were sonicated in acetone, ethanol, and water for $90 \mathrm{~s}$ respectively. And finally, GCE was dried under the argon gas.

\subsection{Electrode modification}

GO synthesis was carried out using the Hummers method [4]. Prepared GO was diluted to concentration of $0.5 \mathrm{mg} \cdot \mathrm{mL}^{-1}$ and depositedon the working electrode surface GCE [5]. As reference electrode $\mathrm{Ag} / \mathrm{AgCl}$ $1 \mathrm{M} \mathrm{KCl}$ and platinum electrode were used. All electrochemical measurements ware performed with potentiostat/ galvanostat (Autolab PGSTAT 101, Metrohm, Herisau, Switzerland) and for data evaluation software NOVA 2.1 was used. On the immersed GCE in the GO solution current $+1 \mathrm{~V}$ for $480 \mathrm{~s}$ was applied. Next electrode was slightly rinsed in MilliQ water. The deposited film of $\mathrm{GO}$ was reduced by performing cyclic voltammetry $(\mathrm{CV})$ (scan from $0.0 \mathrm{~V}$ to $-1.5 \mathrm{~V}$, scan rate $50 \mathrm{mV} \cdot \mathrm{s}^{-1}$ ) in $0.2 \mathrm{M}$ acetate buffer $(\mathrm{pH} 5)$ to produce reduced graphene oxide (erGO) [5]. The other step was electrodeposition of $\mathrm{AN}_{-} \mathrm{SO}_{3}$ - in $\mathrm{PBS}_{\text {buffer using } \mathrm{CV}}$ (scan from $+1.5 \mathrm{~V}$ to $-0.5 \mathrm{~V}$, scan rate $20 \mathrm{mV} \cdot \mathrm{s}^{-1}, 8$ cycles) [6]. Subsequently the GCE was immersed in a $\mathrm{PCl}_{5}$ solution for 30 min to transfer the sulfonic groups on the sulfonyl groups on the GCE modified with AN$\mathrm{SO}_{3-}$ [6].

The last step was the immobilization of the target miRNA complementary sequence to. Complementary DNA sequence was diluted to $1 \mu \mathrm{M}$ and then heated up to $80^{\circ} \mathrm{C}$ for $2 \mathrm{~min}$. After that, $10 \mu \mathrm{l}$ of DNA was dropped on the surface of GCE and placed in an oven where it remained for $90 \mathrm{~min}$ at $80^{\circ} \mathrm{C}$ [7]. After drying, electrode was rinsed with TE buffer. Electrical impedance spectroscopy method (EIS) was set at a DC potential of $0.23 \mathrm{~V}$ 
between frequencies of $0.01 \mathrm{~Hz}$ to $10 \mathrm{kHz}$ with an $\mathrm{AC}$ of $5 \mathrm{mV}$ [7]. The miRNA hybridization was carried out at room temperature for $45 \mathrm{~min}$ in TE buffer.

\section{RESULTS AND DISCUSION}

\subsection{Electrochemical reduction of $\mathbf{G O}$}

Figure 1 shows GO reduction process. In the voltammograms, the irreversible reduction signal at $-1.1 \mathrm{~V}$ can be observed in the first cycle which completely disappeared in others. This is the verification that the reduction went correctly and that the erGO arose on the electrode.

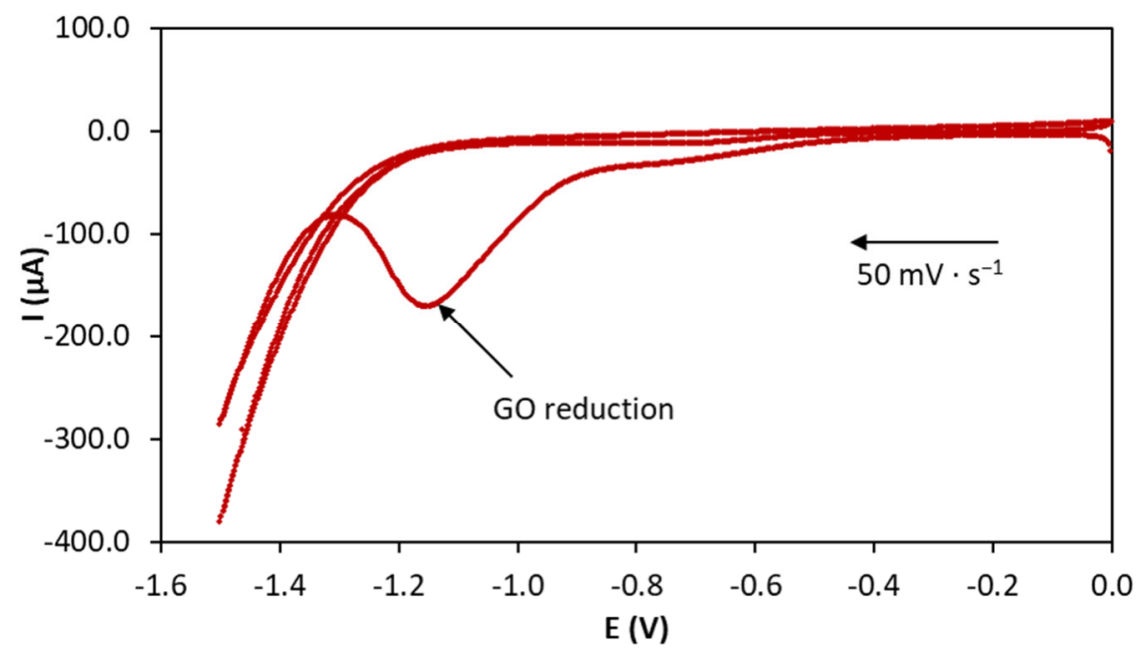

Figure 1 Reducing of GO by $\mathrm{CV}$ in $0.2 \mathrm{M}$ acetate buffer

$\mathrm{GO}$ is a non-conductive material, on the contrary erGO is conductive very well [3]. This is supported by the Nyquist plots in Figure 2, where erGO has a much lower resistance than GO.

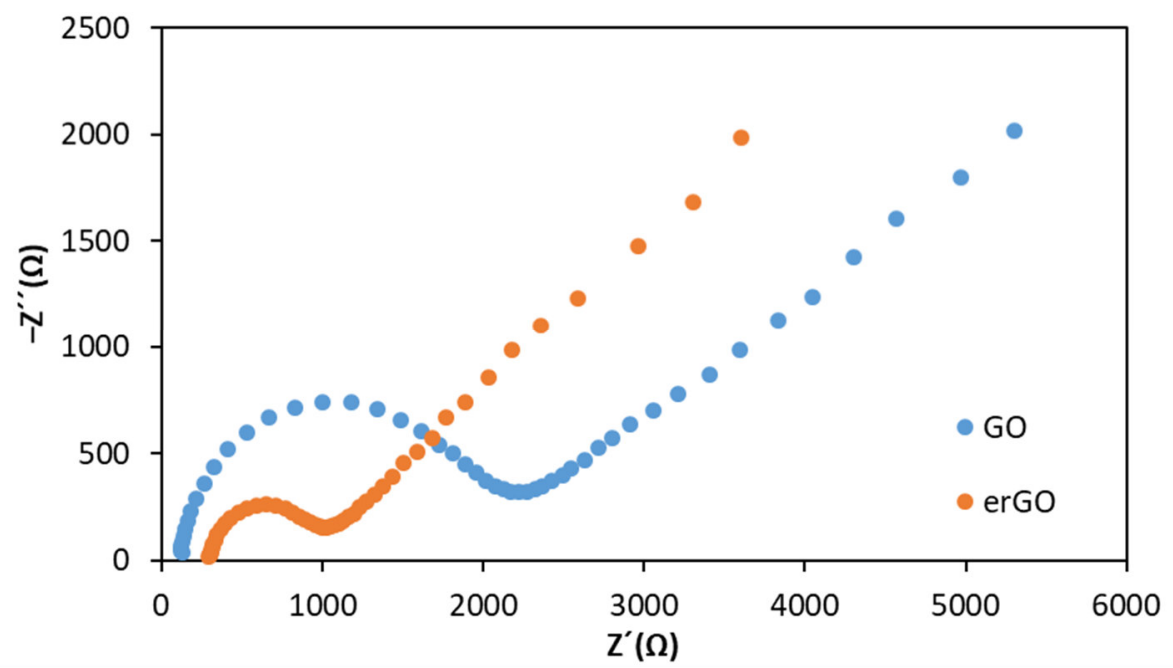

Figure 2 Nyquist plots from measurement of GCE with deposited GO and GCE with erGO

\section{2. $\mathrm{AN}-\mathrm{SO}_{3}$ - electrodeposition on GCE}

Electrodeposition of $\mathrm{AN}-\mathrm{SO}_{3}$ - was carried out on the electrode surface by $\mathrm{CV}$, running 8 cycles until the stable layer was achieved [8]. In Figure 3 we can see two oxidation peaks at the position $0.2 \mathrm{~V}(\mathrm{P} 1)$ and $0.65 \mathrm{~V}(\mathrm{P} 2)$ 
and two reduction peaks at position $0.1 \mathrm{~V}(\mathrm{P} 3)$ and $-0.2 \mathrm{~V}(\mathrm{P} 4)$. With an increasing number of cycles, the layer from $\mathrm{AN}-\mathrm{SO}_{3}$ - is growing thus the deposit is more stable.

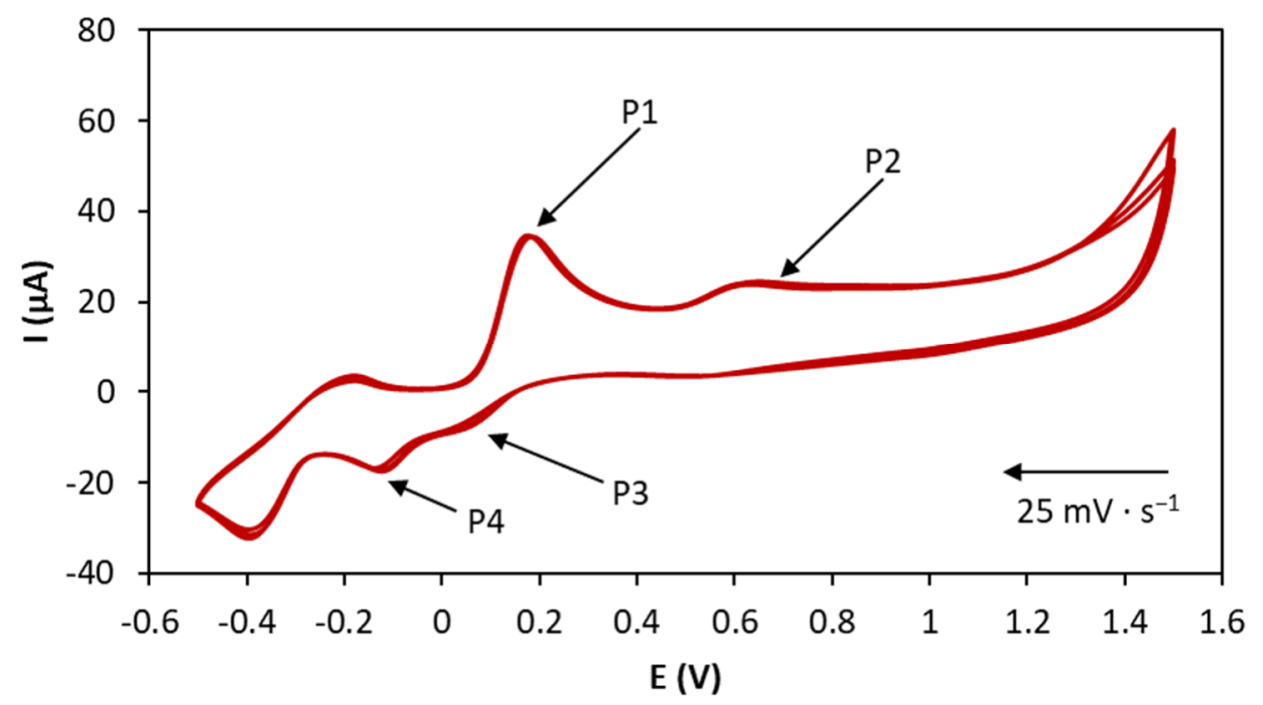

Figure 3 Electrodeposition $\mathrm{AN}_{-} \mathrm{SO}_{3}$ - by $\mathrm{CV}$

\subsection{Hybridization of miRNA-21 with DNA probe}

In this part of the experiment different concentrations of miRNA-21 target were measured with the prepared concept of the biosensor. The data were measured with EIS. Concentrations ranged from $10^{-16}$ (100 aM) to $10^{-10}(100 \mathrm{pM})$ (Figure 4). The target miRNA-21 was dissolved in TE buffer at exact concentration and incubated for $45 \mathrm{~min}$ with a prepared electrode at room temperature. Irregular results were obtained at lower concentrations than $100 \mathrm{aM}$, therefore they were not included in the calibration curves. Measurement was processing by NOVA 2.1 software. Data generated for calibration were counted as the difference between the final point and the starting point of the Nyquist semi-circle graph.

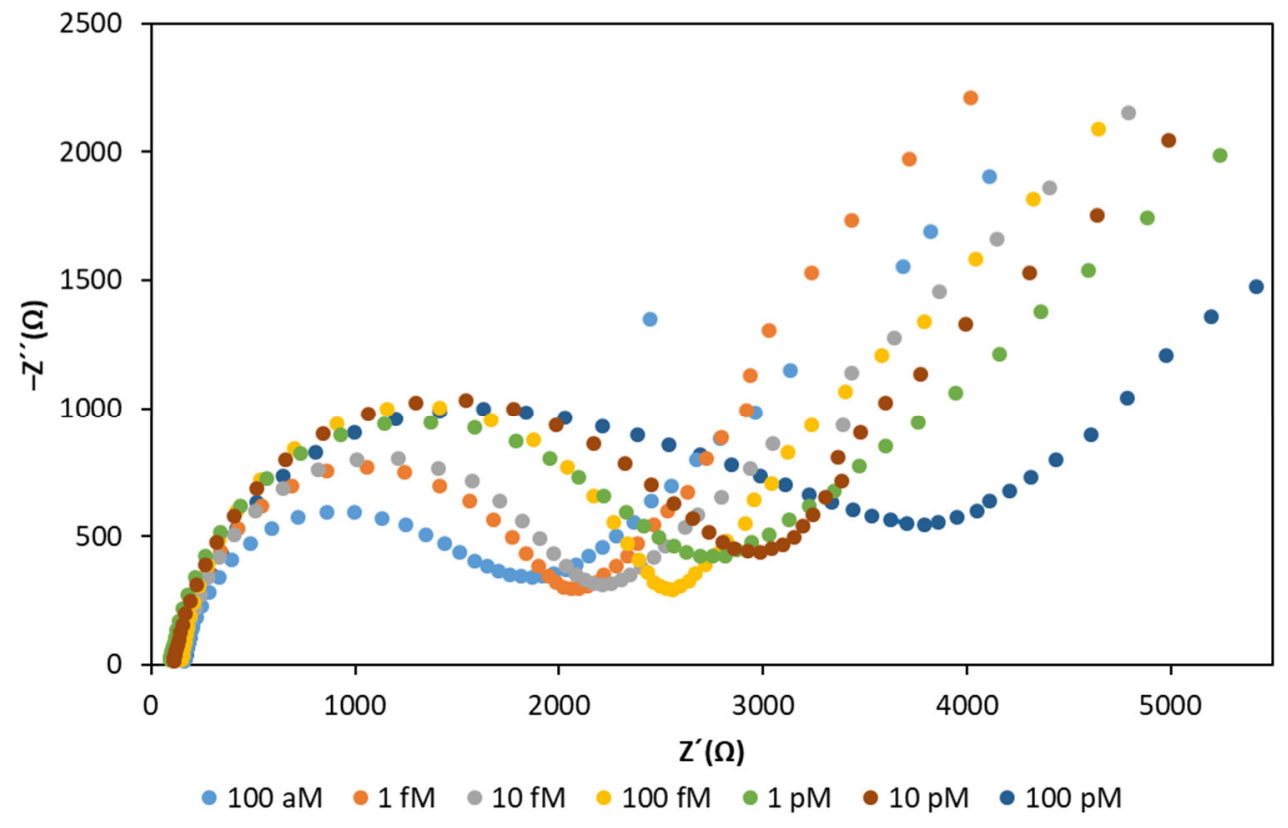

Figure 4 Nyquist plots: various concentrations of miRNA-21, measured with EIS 


\subsection{Calibration curve}

Consequently, the calibration curve was prepared to evaluate data from the measurement. For showing a linear dependence the concentration data are presented in Figure 5 as $\log c(\mathrm{M})$ values. Calibration starts with $10^{-16}(100 \mathrm{aM})$ and ends with $10^{-10}(100 \mathrm{pM})$ concentration. LOD which we reached by measurement is 100 aM and counted LOD is $111 \mathrm{aM}$, then the counted LOQ is $367 \mathrm{aM}$.

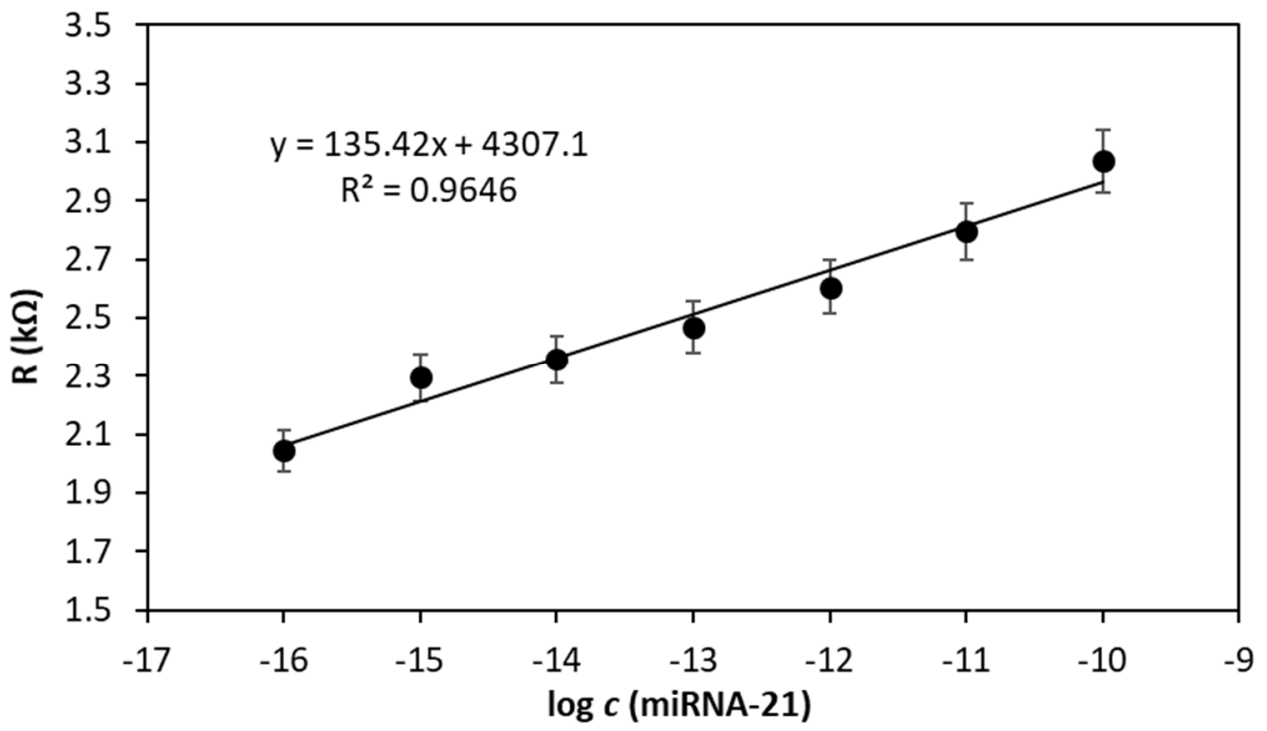

Figure 5 Calibration curve of different miRNA-21 concentrations

Table 1 Analytical table for LOD and LOQ

\begin{tabular}{|c|c|c|c|c|c|}
\hline Sample & Regression Equation & $\begin{array}{c}\text { Linear dynamic } \\
\text { range } \log \boldsymbol{c}(\mathbf{M})\end{array}$ & $\mathbf{R}^{\mathbf{2}}$ & $\begin{array}{c}\text { LOD } \\
(\mathbf{a M})\end{array}$ & LOQ \\
\hline miRNA-21 & $y=135.42 x+4307.1$ & -10 to -16 & 0.9646 & 111 & 367 \\
\hline
\end{tabular}

\section{CONCLUSION}

Sensitive biosensor for the detection of miRNA-21 was designed. For better sensitivity of the biosensor erGO

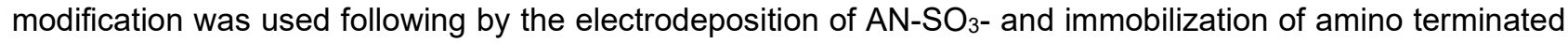
DNA probe via the sulfonamide coupling reaction. LOD is calculated to be low as $111 \mathrm{aM}$ and LOQ 367 aM. These results show an excellent sensitivity of the proposed biosensor, which is necessary for the detection of miRNA molecule because of its low concentrations in body fluids.

\section{ACKNOWLEDGEMENTS}

This research was carried out under the project CEITEC 2020 (LQ1601) with financial support from the Ministry of Education, Youth and Sports of the Czech Republic under the National Sustainability Programme II.

\section{REFERENCES}

[1] DONG, Haifeng, LEI, Jianping, DING, Lin, WEN, Yonggiang, JU, Haungxian, ZHANG, Xueji. MicroRNA: function, detection, and bioanalysis. Chemical reviews. 2013. vol. 113, no. 8, pp. 6207-6233.

[2] SHENOUDA, Sylvia K. and ALAHARI, Suresh K. MicroRNA function in cancer: oncogene or a tumor suppressor? Cancer and metastasis reviews. 2009. vol. 28, no. 3-4, p. 369. 
[3] SREEPRASAD, Theruvakkatil, BERRY, Vikas. How do the electrical properties of graphene change with its functionalization? Small. 2013. vol. 9, no. 3, pp. 341-350.

[4] HUMMERS, William J. and OFFEMAN, Richard. E. Preparation of graphitic oxide. Journal of the american chemical society. vol. 80, no. 6, pp. 1339-1339.

[5] KUDR, Jiri, RICHTERA, Lukas, NEJDL, Lukas, XHAXHIU, Kledi, VITEK, Petr, RUTKAY-NEDECKY, Branislav, HYNEK, David, KOPEL, Pavel, ADAM, Vojtech, KIZEK, Rene. Improved electrochemical detection of zinc ions using electrode modified with electrochemically reduced graphene oxide. Materials. 2016. vol. 9, no. 1, p. 31.

[6] WANG, Qingxiang, DING, Yingtao, GAO, Feng, JIANG, Shulian, ZHANG, Bin, NI, Jiancong, GAO, Fei. A sensitive DNA biosensor based on a facile sulfamide coupling reaction for capture probe immobilization. Analytica chimica acta. 2013. vol. 788, pp. 158-164.

[7] SMITH, Daniel A., NEWBURY, Lucy J., DRAGO, Guido, BOWEN, Timothy, REDMAN, James E. Electrochemical detection of urinary microRNAs via sulfonamide-bound antisense hybridisation. Sensors and Actuators $B$ : Chemical. 2017. vol. 253, pp. 335-341.

[8] NOMURA, Tsuyoshi. Alternating current polarographic determination of microgram amounts of iodide ion by means of the catalytic oxidation of 1-amino-2-naphthol-4-sulfonic acid. Journal of Electroanalytical Chemistry and Interfacial Electrochemistry. 1982. vol. 139, no. 1, pp. 97-104. 